\title{
Neuroendocrine Dysfunction in PCOS: A Critique of Recent Reviews
}

\section{Keywords:}

Polycystic ovary syndrome

Luteinizing hormone

Hyperandrogenism

Gonadotropin releasing hormone
Reprint Requests:

Dr. Suhail A.R. Doi

Department of Medicine

Kuwait University

P.O. Box 24923 Safat

| 3 | 10 Kuwait

Fax +447092377990

Email: sardoi@gmx.net
Received: April, 19, 2008

Revised: July 17, 2008

Accepted: July 23, 2008

doi: $10.3121 / \mathrm{cmr} .2008 .796$

\author{
Suhail A. R. Doi, PhD, FRCP
}

$\mathrm{B}$

lank et al ${ }^{1,2}$ have written comprehensively on neuroendocrine dysfunction in polycystic ovary syndrome (PCOS) in the recent literature, but have made several assertions which I find difficult to tie in with the current knowledge base. In this critique, I therefore focus on the three areas of disagreement below and argue the case for a more satisfactory explanation of these three issues based on the evidence available to us today and studies from our group.

\section{The Relationship Between Luteinizing Hormone (LH) and Hyperandrogenism}

Blank et $\mathrm{al}^{2}$ state that "...the concomitant disruption of neuroendocrine function would serve to further exacerbate hyperandrogenaemia..." and this is also depicted in their schema. ${ }^{1,2}$ Therefore, in their reviews they tend to imply that LH excess worsens hyperandrogenism through ovarian stimulation of androgenesis. This is unlikely to be valid despite the fact that a major neuroendocrine component of PCOS involves alterations in LH secretion, and primary LH excess has long been considered the cause of the excess ovarian androgen secretion in PCOS. This concept simply arose because of the known stimulatory effect of LH on theca cell function and the elevation of serum LH levels at baseline and in response to gonadotrophin releasing hormone $(\mathrm{GnRH})$ in classic PCOS. Such a primary role of LH excess is arguable, however. Theca cells from polycystic ovaries secrete abnormal amounts of steroids in culture, both before and after LH stimulation. ${ }^{3}$

Furthermore, when patients with PCOS are given a fixed dose of the LH analogue human chorionic gonadotropin, they have 17-hydroxyprogesterone and androstenedione hyper-responses ${ }^{4,5}$ that continue to be manifest despite correction of their baseline $\mathrm{LH}$ abnormality by 1 month of $\mathrm{GnRH}$ agonist treatment. ${ }^{6}$ This observation even led to the use of GnRH as a specific test of the combined function of the ovarian follicular compartments.

Patients with classic PCOS (hyperandrogenism with elevated LH or ultrasonographic abnormality or both) will characteristically respond to such a GnRH agonist challenge test with hyper-responsiveness of plasma 17-hydroxyprogesterone and, to a lesser extent, androstenedione. ${ }^{7,8}$ This pattern 
of steroid secretion suggests that there is generalized dysregulation of ovarian androgen secretion, which is particularly prominent at the level of 17-hydroxylase and 17, 20 -lyase activities. This is in contrast to normal women who, when given a single dose of a potent GnRH agonist like nafarelin or leuprolide, have a premature $\mathrm{LH}$ and follicle stimulating hormone surge that is of preovulatory magnitude 7,8 and in whom plasma estradiol and estrone rise 3 -fold within 24 hours. This process in normal women is fairly efficient and there is relatively little elevation in the blood level of estradiol precursors.

The former type of ovarian dysfunction (the excess rise in estrogen previously mentioned) typical of PCOS has been found in more than half of hyperandrogenic patients, many of whom lack the classic criteria for the diagnosis of PCOS. This was demonstrated in a study ${ }^{9}$ where an elevated plasma 17-hydroxyprogesterone response to $\mathrm{GnRH}$ agonist was found in $58 \%$ of hyperandrogenic patients. Interestingly, $96 \%$ of such responders had an abnormal dexamethasone androgen-suppression test, suggesting that it too was equally specific for PCOS.

It can be argued that these data, however, do not resolve the question of whether the abnormal theca cell response is simply a consequence of residual thecal cell hyperplasia from antecedent LH stimulation, ${ }^{10,11}$ but data have begun to accumulate that are against such a primary role for LH excess in this type of ovarian dysfunction. To begin with, such ovarian syndromes (ovarian hyperandrogenism) have the same frequency with or without the classic PCOS feature of LH excess ${ }^{9}$ even though it could be argued that these patients may secrete an LH molecule with enhanced bioactivity, ${ }^{12,13}$ or that serum gonadotropin levels inversely correlate with the adiposity of patients with PCOS, 14,15 and as such the hyperinsulinemia of obesity amplifies the effect of normal gonadotropin levels. Perhaps the most important factor weighing against a primary role of LH excess as a cause of hyperandrogenism is the desensitization process.

The downregulation response in normal women (called homologous desensitization) is because normal ovarian thecal cells respond to $\mathrm{LH}$ in a biphasic manner, increasing their steroid output in response to LH levels only to a point (at LH levels in the range normal for the early to midfollicular phase of the menstrual cycle), and ceasing to respond when LH levels exceed this. The process of desensitization may in part involve downregulation of the number of $\mathrm{LH}$ receptor sites on thecal cells, and may be partly due to downregulation of thecal androgen biosynthesis by the local paracrine factors produced by the granulosa cells in response to LH. ${ }^{16}$ In PCOS, there is escape from such desensitization and implies that the ovarian dysfunction must be independent of LH excess.

Normal thecal cells are very sensitive to the downregulating effect of LH levels within the physiologic range. ${ }^{3,17}$ Maximal stimulation of 17-hydroxyprogesterone and androstenedione in culture normally occurs at LH concentrations approximating the upper portion of the normal range for follicular phase serum LH levels, and a further increase in $\mathrm{LH}$ dosage leads to no further rise. Nevertheless, the possibility exists that the disproportionate 17-hydroxyprogesterone response to stimulation by gonadotropins in patients with PCOS (and functional ovarian hyperandrogenism) might be explained by their LH levels on the LH-steroid dose-response curve being at a higher point where there could be incipient downregulation of 17,20-lyase at LH levels stimulatory to 17-hydroxylation. To refute this possibility, workers have shown that LH-steroid dose-response relationships during GnRH agonist tests ${ }^{18}$ are similarly abnormal in patients with or without elevated serum LH levels. Following GnRH agonist administration, the responses of estradiol fall along the normal LH-steroid dose-response slope, but those of estradiol precursors do not. The apparent slope of the LH-steroid dose-response relationship is markedly abnormal for 17-hydroxyprogesterone, above but parallel to normal for androstenedione, and slightly increased for testosterone.

These data suggest that although 17,20-lyase efficiency is increased, it is increased less than that of 17-hydroxylation. These results also suggest that patients with functional ovarian hyperandrogenism, regardless of whether they have classic or nonclassic PCOS, have an LH-17-hydroxyprogesterone dose-response curve that is shifted upward and to the left. Since the steroid responses do not fall along the normal LH-steroid dose-response curve, the defect in steroidogenesis must therefore be the result of escape from normal downregulation of thecal cell secretion rather than over-stimulation by LH. If we accept these results, then the fundamental defect underlying the androgen excess of PCOS is ovarian hyper-responsiveness to gonadotropin action because of escape from downregulation and not a primary result of excess LH per se.

In vitro studies using cultured individual theca cells from polycystic ovaries also seem to be consistent with this conclusion and have again shown that the LH-steroid dose-response curves are displaced upward and leftward. ${ }^{3}$ Using a system of propagating human theca cells in long-term culture, other workers have also shown that enhanced production of progesterone, 17- $\alpha$-hydroxyprogesterone, and testosterone is a persistent biochemical phenotype of PCOS theca cells. ${ }^{19}$ As these theca cell cultures can be maintained through multiple population doublings, the increased steroidogenic activity of PCOS theca cells compared with normal theca cells has been thought to be unlikely to reflect the influence of in vivo hormonal stimulation (i.e., increased LH levels associated with PCOS).

Taken together, all these observations suggest that dysregulation of androgen biosynthesis is an intrinsic property of PCOS theca cells. Nevertheless, it can still be argued that the increased transcription of steroidogenic 
enzyme genes could still be the result of a stable metabolic imprinting of the theca cells imposed in vivo and retained in vitro, ${ }^{19,20}$ rather than genetic imprinting. Also, PCOS theca cells may have increased sensitivity to some component of the culture medium that stimulates the expression of steroidogenic enzymes. ${ }^{19}$ Studies of decreased in vivo steroidogenesis after pharmacologic therapy suggest that the latter mechanism may be important in the genesis of the hyperandrogenism, but this does not necessarily exclude a genetic factor that results in hypersensitive theca cells. For example, increased synthesis of testosterone and its precursors in vivo after human chorionic gonadotropin is alleviated by metformin therapy ${ }^{21}$ but insulin is unlikely to be directly involved as both normal and PCOS theca cells respond equivalently to insulin in terms of steroid production..$^{19} \mathrm{In}$, conclusion, the evidence suggests that $\mathrm{LH}$ is not a major player in the hyperandrogenism of PCOS, and excess LH may be a consequence of the metabolic alterations in PCOS.

\section{Why is There LH Excess in the First Place?}

Blank et $\mathrm{al}^{2}$ go on in their review to propose that neuroendocrine abnormalities are partly related to androgen-dependent decreases in GnRH pulse generator sensitivity to the negative feedback actions of ovarian steroids. Our group had already proposed this in $2005,{ }^{22}$ and hence their claim is not valid. Second, we have taken this concept much further than is depicted by Blank et al in their reviews. ${ }^{1,2}$ We demonstrate that rather than testosterone, there is a significant association of elevated androstenedione levels with neuroendocrine dysfunction in PCOS. ${ }^{22}$ This conclusion was reached via inferential studies as follows. Since it is known that the absence of physiologic levels of estradiol allows rises in gonadotrophins in both men ${ }^{23}$ and women, ${ }^{24}$ this suggests that it is estradiol rather than androgens that modulate GnRH feedback. However, experiments in the Rhesus monkey have shown that the suppression of pulsatile $\mathrm{GnRH}$ release is relatively constant in the face of widely varying levels of estradiol in the peripheral circulation, ${ }^{25}$ suggesting that modulation of the hypothalamic $\mathrm{GnRH}$ "pulse generator" by estradiol in the physiologic range is subject to another factor. This factor must be ovarian since total blockade of the electrical activity of this pulse generator has been demonstrated in ovariectomized monkeys by physiological levels of exogenous estradiol. ${ }^{25}$ This raises the possibility that estradiol feedback is at the hypothalamus but is modulated by an ovarian factor that is normally present during the menstrual cycle and keeps this neuronal system uncoupled from excessive inhibition by estrogen. We then demonstrate by mathematical modeling 22 that androstenedione might be the factor that enhances uncoupling of hypothalamic GnRH secretion from the effect of estradiol, thus leading to accelerated activity of this pulse generator. This uncoupling hypothesis is not new and was actually first suggested as a mechanism for excess LH in PCOS by Yen ${ }^{26}$ back in 1980. What had not been recognized then was the putative role of androgens in the pathogenesis of this effect.
Of the various factors identified in our study, ${ }^{22}$ we only were able to associate androstenedione with hypothalamic uncoupling since insulin resistance was the only other (non-estradiol) factor identified by our model as being a predictor of LH status but was not associated with high LH. In retrospect, other studies ${ }^{27}$ also support such a role for androgens, since it has been shown that serum testosterone is the baseline variable that differs between LH groups in PCOS, and controlling for testosterone removes the differences in LH responsiveness between groups. As testosterone and androstenedione are linearly related in PCOS, 22 this could very well have been an effect of androstenedione rather than testosterone. In our study, almost none of the women with high LH had a normal androstenedione level, suggesting that androstenedione might be the factor that uncouples $\mathrm{GnRH}$ from inhibition by estradiol. Indeed the data previously reported by the same group 28 supports our finding, since they demonstrate that blockade of androgen action for 5 weeks restores the sensitivity of the GnRH pulse generator to feedback inhibition by estradiol and progesterone. Further support of this is lent to by studies where anti-androgens like flutamide do reduce LH levels in women with PCOS but not in normal women. Indeed, flutamide administration to hyperandrogenic women is followed by a decrease in LH pulse amplitude associated with an apparent decline in mean $\mathrm{LH}$ concentrations. ${ }^{29-31}$ Androstenedione concentrations significantly decrease during flutamide administration, while sex-hormone-binding globulin and estradiol are not affected. ${ }^{31}$ On the other hand, reduction in estradiol alone via treatment with aromatase inhibitors does not alter $\mathrm{LH}$ significantly and in fact increases LH pulse amplitude and frequency slightly in association with increased androgens. ${ }^{32}$ Furthermore, in patients with androgen secreting ovarian neoplasms, LH is high but returns to normal after tumor removal. ${ }^{33}$ Other studies have also documented that decreases in circulating androgens precede the fall in $\mathrm{LH}$ and ovulation following both ovarian wedge resection ${ }^{34}$ and ovarian cauterization. ${ }^{35}$

However, in addition to a high androstenedione, a high normal estradiol seems to be a prerequisite for neuroendocrine dysfunction. Such estradiol levels alone, however (in the absence of high androstenedione), were very rarely associated with high LH. ${ }^{22}$ This suggests that both hypothalamic uncoupling and an excess estradiol state are required to lead to neuroendocrine dysfunction. The mechanism of this effect might be related to the fact that estradiol is also thought to sensitize the pituitary to GnRH, providing part of the basis for the LH surge ${ }^{36}$ and, at least in humans, there is also evidence for reduced production of $\mathrm{GnRH}$ at the time of the LH surge, placing even greater importance on such estradiol-mediated gonadotrope sensitivity to GnRH. ${ }^{37}$ Estrogen has also been shown to increase the fraction of gonadotropes that respond to $\mathrm{GnRH},{ }^{38}$ such that small GnRH pulses (normally insufficient to stimulate LH secretion) may result in discernible $\mathrm{LH}$ 
pulses. Hypothalamic uncoupling may therefore enhance this positive feedback mechanism at the pituitary level in PCOS, and indeed this has been shown in other studies to correlate with the basal levels of both estrone and 17- $\beta$-estradiol. ${ }^{39}$ Studies of normal women suggest a threshold for the estradiol effect at a minimum serum estradiol concentration sustained at $734 \mathrm{pmol} / \mathrm{L}(200 \mathrm{pg} / \mathrm{mL})$ for at least 50 hours. ${ }^{40}$ In PCOS, hypothalamic uncoupling may reduce this threshold and result in pituitary sensitization after chronic exposure to just high-normal estradiol levels as demonstrated recently by us. ${ }^{22}$

\section{What is the Role of Obesity and Insulin Resistance?}

Blank et $\mathrm{al}^{2}$ imply in their review that hyperinsulinemia may bring about important changes in hypothalamic function indirectly by increasing androgen levels. On the contrary, one of the androgens, androstenedione, has clearly been shown to be negatively associated with body mass index (BMI) (and presumably insulin levels) and this decrease occurs in both PCOS and non-PCOS related obesity, ${ }^{41-43}$ while testosterone levels and the free androgen index remain constant throughout the entire range of BMI in controls. ${ }^{41}$ The view put forward by Blank et $\mathrm{al}^{2}$ is based mainly on evidence from studies of insulin lowering $44-50$ and may not necessarily be a correct interpretation of the relationship between insulin and neuroendocrine dysfunction. Studies that acutely increased insulin have shown that there are no significant correlations between either basal, peak, or area under the curve-insulin response during the oral glucose tolerance test and intravenous glucose tolerance test with basal testosterone or androstenedione concentrations or between insulin and androgen levels measured at 30-minute intervals throughout the oral glucose tolerance test. 51 Also, clinical studies of insulin infusion for several hours to normal and hyperandrogenic women fail to increase testosterone levels. ${ }^{52}$ It is possible, therefore, that the effect on androgens demonstrated in the literature is merely associated with insulin lowering and in fact may result from changes in insulin-like growth factor-1 induced paracrine regulation that influences LH-induced androgen secretion. ${ }^{53,54}$ Indeed, we were only able to demonstrate either no overall change in testosterone with obesity or a clear decline in androstenedione, ${ }^{22}$ except for an increase in free androgen index because of insulin mediated decreases in sex hormone-binding globulin.

It is also well known that obese PCOS patients, who are also expected to be hyperinsulinemic, demonstrate reduced values for LH compared with leaner PCOS patients who tend to have higher follicular phase values than normal women. ${ }^{14,55}$ Nevertheless, LH pulse frequency is increased in women with PCOS in comparison with normal women across the spectrum of BMI with no difference between lean and obese PCOS patients. ${ }^{14,55}$ The evidence on the interaction between LH and obesity in PCOS is conflicting with some studies, suggesting that a higher BMI is associated with a lower basal LH, ${ }^{56-59}$ while others do not. ${ }^{60,61}$ We could demonstrate no difference when all PCOS women were analyzed but when only oligomenorrhoic women were included in the analysis; then a clear interaction between LH and BMI emerged. ${ }^{22}$ The varying results in the literature may be a consequence of the varying definitions of PCOS utilized and suggests that in the absence of obesity, the mere presence of regular cycles in lean PCOS may preclude the occurrence of neuroendocrine dysfunction. In the presence of irregular cycles, mainly lean women have neuroendocrine dysfunction, suggesting that factors associated with obesity exert an effect on endogenous GnRH action at the central level in PCOS women, ${ }^{14}$ and in contrast to the conclusions reached by Blank et al, ${ }^{2}$ our results suggest that a fall in androstenedione and increase in insulin 22,62 might be the factors that preclude the occurrence of neuroendocrine dysfunction.

We have also documented that PCOS women with neuroendocrine dysfunction are anovulatory. ${ }^{63}$ We also found that in women without neuroendocrine dysfunction, insulin resistance was associated with anovulation. ${ }^{63}$ Other studies 64-66 confirm our findings that insulin resistance is associated with anovulation. Indeed, studies that use ovarian morphology to classify women with PCOS have found that only anovulatory hyperandrogenic women with polycystic ovarian morphology are insulin resistant. ${ }^{65-67}$ Women with regular ovulatory menses and hyperandrogenism ${ }^{64}$ or with PCOS detected by ovarian ultrasound 65,66 are not insulin resistant. We have shown in a recent study 22 that alterations in steroid hormones lead to neuroendocrine dysfunction and anovulation, and in another study 63 that alterations in progesterone/estradiol ratio leads to anovulation. Insulin resistance seems associated with both an altered central response to the steroid hormones leading to absence of neuroendocrine dysfunction in PCOS women (despite high levels of both androstenedione and estradiol), as well as altered progesterone/estradiol ratio leading to anovulation. Indeed, those women without excess LH are more obese and more insulin resistant. ${ }^{22}$ Since multivariate analysis retains insulin sensitivity over BMI, this suggests a direct role for insulin resistance in decreasing $\mathrm{LH}$, even in the presence of increased androstenedione. Since LH secretion and gonadotrophin responses to GnRH have not been shown to be directly influenced by insulin administration, ${ }^{68}$ again this effect of insulin resistance, while associated with excess insulin, seems also to be mediated indirectly (we do not know how) and not directly through an increase in insulin levels. That the overall effect demonstrated in our studies is an interaction between the effects of steroid hormones and insulin resistance is further suggested by the fact that in other studies the $\mathrm{LH} /$ follicle stimulating hormone ratio does not change with differences in insulin status alone. 69

\section{Conclusion}

Ultimately, it is getting clearer that the LH dysregulation associated with PCOS is not primary but secondary to the peripheral events within the ovary. However, in contrast to what has been published recently, the mechanism of neuroendocrine dysfunction resulting in an elevated LH in 
PCOS may be an uncoupling of hypothalamic estradiol inhibition by elevated ovarian androstenedione. This abnormal secretion of ovarian androstenedione seems to be an intrinsic property of PCOS theca/granulosa cells. At a particular threshold (determined by estradiol levels), this uncoupling is associated with an estradiol-related sensitization of pituitary LH release and hence an increase in LH secretion. Finally, a case has been made to support the view that in some hyperandrogenic women with PCOS, obesity leads to decreased androstenedione synthesis or the development of insulin resistance, both of which seem to decrease LH secretion independently of each other.

\section{References}

1. Blank SK, McCartney CR, Helm KD, Marshall JC. Neuroendocrine effects of androgens in adult polycystic ovary syndrome and female puberty. Semin Reprod Med 2007;25:352-359.

2. Blank SK, McCartney CR, Marshall JC. The origins and sequelae of abnormal neuroendocrine function in polycystic ovary syndrome. Hum Reprod Update 2006;12:351-361.

3. Gilling-Smith C, Willis DS, Beard RW, Franks S. Hypersecretion of androstenedione by isolated thecal cells from polycystic ovaries. J Clin Endocrinol Metab 1994;79:1158-1165.

4. Ibañez L, Hall JE, Potau N, Carrascosa A, Prat N, Taylor AE.. Ovarian 17-hydroxyprogesterone hyperresponsiveness to gonadotropin-releasing hormone $(\mathrm{GnRH})$ agonist challenge in women with polycystic ovary syndrome is not mediated by luteinizing hormone hypersecretion: evidence from $\mathrm{GnRH}$ agonist and human chorionic gonadotropin stimulation testing. J Clin Endocrinol Metab 1996;81:4103-4107.

5. Levrant SG, Barnes RB, Rosenfield RL. A pilot study of the human chorionic gonadotrophin test for ovarian hyperandrogenism. Hum Reprod 1997;12:1416-1420.

6. Gilling-Smith C, Story H, Rogers V, Franks S. Evidence for a primary abnormality of thecal cell steroidogenesis in the polycystic ovary syndrome. Clin Endocrinol (Oxf) 1997;47:93-99.

7. Barnes RB, Rosenfield RL, Burstein S, Ehrmann DA. Pituitary-ovarian responses to nafarelin testing in the polycystic ovary syndrome. N Engl J Med 1989; 320:559-565.

8. Ehrmann DA, Barnes RB, Rosenfield RL. Polycystic ovary syndrome as a form of functional ovarian hyperandrogenism due to dysregulation of androgen secretion. Endocr Rev 1995; 16:322-353.

9. Ehrmann DA, Rosenfield RL, Barnes RB, Brigell DF, Sheikh Z. Detection of functional ovarian hyperandrogenism in women with androgen excess. N Engl J Med 1992;327:157-162.

10. Rosenfield RL. Is polycystic ovary syndrome a neuroendocrine or an ovarian disorder? Clin Endocrinol (Oxf) 1997; 47:423-424.

11. Sahin Y, Kelestimur F. 17-Hydroxyprogesterone response to buserelin testing in the polycystic ovary syndrome. Clin Endocrinol (Oxf) 1993;39:151-155.

12. Fauser BC, Pache TD, Lamberts SW, Hop WC, de Jong FH, Dahl KD. Serum bioactive and immunoreactive luteinizing hormone and follicle-stimulating hormone levels in women with cycle abnormalities, with or without polycystic ovarian disease. J Clin Endocrinol Metab 1991;73:811-817.

13. Imse V, Holzapfel G, Hinney B, Kuhn W, Wuttke W. Comparison of luteinizing hormone pulsatility in the serum of women suffering from polycystic ovarian disease using a bioassay and five different immunoassays. J Clin Endocrinol Metab 1992;74:1053-1061.
14. Arroyo A, Laughlin GA, Morales AJ, Yen SS. Inappropriate gonadotropin secretion in polycystic ovary syndrome: influence of adiposity. J Clin Endocrinol Metab 1997;82:3728-3733.

15. Taylor AE, McCourt B, Martin KA, Anderson EJ, Adams JM, Schoenfeld D, Hall JE. Determinants of abnormal gonadotropin secretion in clinically defined women with polycystic ovary syndrome. J Clin Endocrinol Metab 1997;82:2248-2256.

16. Rosenfield RL. Ovarian and adrenal function in polycystic ovary syndrome. Endocrinol Metab Clin North Am 1999;28:265-293.

17. Nobels F, Dewailly D. Puberty and polycystic ovarian syndrome: the insulin/insulin-like growth factor I hypothesis. Fertil Steril 1992;58:655-666.

18. Rosenfield RL, Barnes RB, Ehrmann DA. Studies of the nature of 17-hydroxyprogesterone hyperresponsiveness to gonadotropin-releasing hormone agonist challenge in functional ovarian hyperandrogenism. J Clin Endocrinol Metab 1994;79:1686-1692.

19. Nelson VL, Legro RS, Strauss JF 3rd, McAllister JM. Augmented androgen production is a stable steroidogenic phenotype of propagated theca cells from polycystic ovaries. Mol Endocrinol 1999;13:946-957.

20. Strauss JF 3rd, Wood JR, Christenson LK, McAllister JM. Strategies to elucidate the mechanism of excessive theca cell androgen production in PCOS. Mol Cell Endocrinol 2002; 186:183-188.

21. Koivunen RM, Morin-Papunen LC, Ruokonen A, Tapanainen JS, Martikainen HK. Ovarian steroidogenic response to human chorionic gonadotrophin in obese women with polycystic ovary syndrome: effect of metformin. Hum Reprod 2001;16:2546-2551.

22. Doi SA, Al-Zaid M, Towers PA, Scott CJ, Al-Shoumer KA. Ovarian steroids modulate neuroendocrine dysfunction in polycystic ovary syndrome. J Endocrinol Invest 2005; 28:882-892.

23. Carani C, Qin K, Simoni M, Faustini-Fustini M, Serpente S, Boyd J, Korach KS, Simpson ER. Effect of testosterone and estradiol in a man with aromatase deficiency. N Engl J Med 1997;337:91-95.

24. Conte FA, Grumbach MM, Ito Y, Fisher CR, Simpson ER. A syndrome of female pseudohermaphrodism, hypergonadotropic hypogonadism, and multicystic ovaries associated with missense mutations in the gene encoding aromatase (P450arom). J Clin Endocrinol Metab 1994;78:1287-1292.

25. Kesner JS, Wilson RC, Kaufman JM, Hotchkiss J, Chen Y, Yamamoto H, Pardo RR, Knobil E. Unexpected responses of the hypothalamic gonadotropin-releasing hormone "pulse generator" to physiological estradiol inputs in the absence of the ovary. Proc Natl Acad Sci U S A 1987;84:8745-8749.

26. Yen SS. The polycystic ovary syndrome. Clin Endocrinol (Oxf) 1980;12:177-207.

27. Patel K, Coffler MS, Dahan MH, Malcom PJ, Deutsch R, Chang RJ. Relationship of GnRH-stimulated LH release to episodic LH secretion and baseline endocrine-metabolic measures in women with polycystic ovary syndrome. Clin Endocrinol (Oxf) 2004;60:67-74.

28. Eagleson CA, Gingrich MB, Pastor CL, Arora TK, Burt CM, Evans WS, Marshall JC. Polycystic ovarian syndrome: evidence that flutamide restores sensitivity of the gonadotropin-releasing hormone pulse generator to inhibition by estradiol and progesterone. J Clin Endocrinol Metab 2000;85:4047-4052.

29. De Leo V, Lanzetta D, D’Antona D, la Marca A, Morgante G. Hormonal effects of flutamide in young women with polycystic ovary syndrome. J Clin Endocrinol Metab 1998;83:99-102. 
30. Sir T. [Do androgens modulate luteinizing hormone secretion in women?]. Rev Med Chil 1997;125:710-718.

31. Sir-Petermann T, Rabenbauer B, Wildt L. The effect of flutamide on pulsatile gonadotrophin secretion in hyperandrogenaemic women. Hum Reprod 1993; 8:1807-1812.

32. Dunaif A, Longcope C, Canick J, Badger T, Crowley WF Jr. The effects of the aromatase inhibitor delta 1-testolactone on gonadotropin release and steroid metabolism in polycystic ovarian disease. J Clin Endocrinol Metab 1985;60:773-780.

33. Dunaif A, Scully RE, Andersen RN, Chapin DS, Crowley WF Jr. The effects of continuous androgen secretion on the hypothalamic-pituitary axis in woman: evidence from a luteinized thecoma of the ovary. J Clin Endocrinol Metab 1984;59:389-393.

34. Judd HL, Rigg LA, Anderson DC, Yen SS. The effects of ovarian wedge resection on circulating gonadotropin and ovarian steroid levels in patients with polycystic ovary syndrome. J Clin Endocrinol Metab 1976;43:347-355.

35. Greenblatt E, Casper RF. Endocrine changes after laparoscopic ovarian cautery in polycystic ovarian syndrome. Am J Obstet Gynecol 1987; 156:279-285.

36. Mahesh VB, Brann DW. Regulation of the preovulatory gonadotropin surge by endogenous steroids. Steroids 1998;63:616-629.

37. Hall JE, Taylor AE, Martin KA, Rivier J, Schoenfeld DA, Crowley WF Jr. Decreased release of gonadotropin-releasing hormone during the preovulatory midcycle luteinizing hormone surge in normal women. Proc Natl Acad Sci U S A 1994;91:6894-6898.

38. Smith PF, Frawley LS, Neill JD. Detection of LH release from individual pituitary cells by the reverse hemolytic plaque assay: estrogen increases the fraction of gonadotropes responding to GnRH. Endocrinology 1984;115:2484-2486.

39. Rebar R, Judd HL, Yen SS, Rakoff J, Vandenberg G, Naftolin F. Characterization of the inappropriate gonadotropin secretion in polycystic ovary syndrome. J Clin Invest 1976; 57:1320-1329.

40. Young JR, Jaffe RB. Strength-duration characteristics of estrogen effects on gonadotropin response to gonadotropin-releasing hormone in women. II. Effects of varying concentrations of estradiol. J Clin Endocrinol Metab 1976;42:432-442.

41. Holte J, Bergh T, Gennarelli G, Wide L. The independent effects of polycystic ovary syndrome and obesity on serum concentrations of gonadotrophins and sex steroids in premenopausal women. Clin Endocrinol (Oxf) 1994; 41:473-481.

42. Dunaif A, Mandeli J, Fluhr H, Dobrjansky A. The impact of obesity and chronic hyperinsulinemia on gonadotropin release and gonadal steroid secretion in the polycystic ovary syndrome. J Clin Endocrinol Metab 1988;66:131-139.

43. Silfen ME, Denburg MR, Manibo AM, Lobo RA, Jaffe R, Ferin M, Levine LS, Oberfield SE. Early endocrine, metabolic, and sonographic characteristics of polycystic ovary syndrome (PCOS): comparison between nonobese and obese adolescents. J Clin Endocrinol Metab 2003;88:4682-4688.

44. Legro RS, Castracane VD, Kauffman RP. Detecting insulin resistance in polycystic ovary syndrome: purposes and pitfalls. Obstet Gynecol Surv 2004;59:141-154.

45. Gambineri A, Pelusi C, Genghini S, Morselli-Labate AM, Cacciari M, Pagotto U, Pasquali R. Effect of flutamide and metformin administered alone or in combination in dieting obese women with polycystic ovary syndrome. Clin Endocrinol (Oxf) 2004;60:241-249.

46. Sattar N, Hopkinson ZE, Greer IA. Insulin-sensitising agents in polycystic-ovary syndrome. Lancet 1998;351:305-307.
47. Seli E, Duleba AJ. Should patients with polycystic ovarian syndrome be treated with metformin? Hum Reprod 2002;17:2230-2236.

48. Loverro G, Lorusso F, De Pergola G, Nicolardi V, Mei L, Selvaggi L. Clinical and endocrinological effects of 6 months of metformin treatment in young hyperinsulinemic patients affected by polycystic ovary syndrome. Gynecol Endocrinol 2002;16:217-224.

49. Ehrmann DA, Schneider DJ, Sobel BE, Cavaghan MK, Imperial J, Rosenfield RL, Polonsky KS. Troglitazone improves defects in insulin action, insulin secretion, ovarian steroidogenesis, and fibrinolysis in women with polycystic ovary syndrome. J Clin Endocrinol Metab 1997; 82:2108-2116.

50. Hasegawa I, Murakawa H, Suzuki M, Yamamoto Y, Kurabayashi T, Tanaka K. Effect of troglitazone on endocrine and ovulatory performance in women with insulin resistance-related polycystic ovary syndrome. Fertil Steril 1999;71:323-327.

51. Buyalos RP, Geffner ME, Watanabe RM, Bergman RN, Gornbein JA, Judd HL. The influence of luteinizing hormone and insulin on sex steroids and sex hormone-binding globulin in the polycystic ovarian syndrome. Fertil Steril 1993; 60:626-633.

52. Diamond MP, Grainger DA, Laudano AJ, Starick-Zych K, DeFronzo RA. Effect of acute physiological elevations of insulin on circulating androgen levels in nonobese women. J Clin Endocrinol Metab 1991;72:883-887.

53. Doi SA, Towers PA, Scott CJ, Al-Shoumer KA. PCOS: an ovarian disorder that leads to dysregulation in the hypothalamic-pituitary-adrenal axis? Eur J Obstet Gynecol Reprod Biol 2005;118:4-16.

54. Bergh C, Carlsson B, Olsson JH, Selleskog U, Hillensjö T. Regulation of androgen production in cultured human thecal cells by insulin-like growth factor I and insulin. Fertil Steril 1993;59:323-331.

55. Morales AJ, Laughlin GA, Butzow T, Maheshwari H, Baumann $\mathrm{G}$, Yen SS. Insulin, somatotropic, and luteinizing hormone axes in lean and obese women with polycystic ovary syndrome: common and distinct features. J Clin Endocrinol Metab 1996;81:2854-2864.

56. Grulet H, Hecart AC, Delemer B, Gross A, Sulmont V, Leutenegger M, Caron J. Roles of LH and insulin resistance in lean and obese polycystic ovary syndrome. Clin Endocrinol (Oxf) 1993;38:621-626.

57. Dale PO, Tanbo T, Vaaler S, Abyholm T. Body weight, hyperinsulinemia, and gonadotropin levels in the polycystic ovarian syndrome: evidence of two distinct populations. Fertil Steril 1992;58:487-491.

58. Ke WX, Shan GQ, Hua SY. Different responses of insulin, C-peptide, and testosterone to an oral glucose tolerance test in two groups of women with polycystic ovarian syndrome. Acta Obstet Gynecol Scand 1996;75:166-169.

59. Banaszewska B, Spaczyński RZ, Pelesz M, Pawelczyk L. Incidence of elevated LH/FSH ratio in polycystic ovary syndrome women with normo- and hyperinsulinemia. Rocz Akad Med Bialymst 2003;48:131-134.

60. Toprak S, Yönem A, Cakir B, Güler S, Azal O, Ozata M, Corakçi A. Insulin resistance in nonobese patients with polycystic ovary syndrome. Horm Res 2001;55:65-70.

61. Tropeano G, Vuolo IP, Lucisano A, Liberale L, Barini A, Carfagna P, Caroli G, Menini E, dell'Acqua S. Gonadotropin levels in women with polycystic ovary syndrome: their relationship to body weight and insulin levels. J Endocrinol Invest 1996;19:139-145.

62. Doi SA, Al-Zaid M, Towers PA, Scott CJ, Al-Shoumer KA. Steroidogenic alterations and adrenal androgen excess in PCOS. Steroids 2006;71:751-759. 
63. Doi SA, Al-Zaid M, Towers PA, Scott CJ, Al-Shoumer KA. Irregular cycles and steroid hormones in polycystic ovary syndrome. Hum Reprod 2005;20:2402-2408.

64. Dunaif A, Graf M, Mandeli J, Laumas V, Dobrjansky A. Characterization of groups of hyperandrogenic women with acanthosis nigricans, impaired glucose tolerance, and/or hyperinsulinemia. J Clin Endocrinol Metab 1987;65:499-507.

65. Robinson S, Kiddy D, Gelding SV, Willis D, Niththyananthan R, Bush A, Johnston DG, Franks S. The relationship of insulin insensitivity to menstrual pattern in women with hyperandrogenism and polycystic ovaries. Clin Endocrinol (Oxf) 1993;39:351-355.

66. Sampson M, Kong C, Patel A, Unwin R, Jacobs HS. Ambulatory blood pressure profiles and plasminogen activator inhibitor (PAI-1) activity in lean women with and without the polycystic ovary syndrome. Clin Endocrinol (Oxf) 1996;45:623-629.

67. Barber TM, Wass JA, McCarthy MI, Franks S. Metabolic characteristics of women with polycystic ovaries and oligo-amenorrhoea but normal androgen levels: implications for the management of polycystic ovary syndrome. Clin Endocrinol (Oxf) 2007;66:513-517.

68. Patel K, Coffler MS, Dahan MH, Yoo RY, Lawson MA, Malcom PJ, Chang RJ. Increased luteinizing hormone secretion in women with polycystic ovary syndrome is unaltered by prolonged insulin infusion. J Clin Endocrinol Metab 2003;88:5456-5461.

69. Fulghesu AM, Cucinelli F, Pavone V, Murgia F, Guido M, Caruso A, Mancuso S, Lanzone A. Changes in luteinizing hormone and insulin secretion in polycystic ovarian syndrome. Hum Reprod 1999;14:611-617.

\section{Author Affiliation}

Suhail A. R. Doi, PhD, FRCP

Division of Endocrinology

Mubarak Al-Kabeer Hospital and

Kuwait University, Kuwait 